\title{
現場固相抽出/黒鉛炉原子吸光法を用いた 河川水中微量モリブデンの定量
}

\author{
山口 貴之 ${ }^{1}$, 清 家 泰 $^{1}$, 奥 村 稔 $^{\circledR 1}$
}

\section{1 緒言}

モリブデンは, 地款の平均含有量で $1.5 \mathrm{mg} \mathrm{kg}^{-1}$ 存在し, 存在量は少ないが, 土壤, 動物, 海水など自然界に広く分 布している ${ }^{1)}$. モリブデンは生体に必須な微量元素の一つ であるが, 一方で過剩摂取すると痛風様症状が出るなど, 人体に悪影響を与えると考えられている ${ }^{1)}$. 島根県東部に はモリブデン鉱床が点在し, 特に大東・山佐地域には日本 最大のモリブデン鉱床区が存在する ${ }^{2)}$. これらの地域では 河川水などにモリブデンが流入していると考えられてお $り^{3)}$, 実際にその一つである大東地域の鉱山下流域では和 牛の被毛が白色化する現象が認められ, 牧草のモリブデン 含量過多によることが原因であると報告されている4．環 境水中において, モリブデンはモリブデン酸イオン $\left(\mathrm{MoO}_{4}{ }^{2-}\right)$ として溶存しており, 環境水中におけるモリブ デンの濃度レベル, 濃度分布を明らかにし, それが何に起 因するかを見いだすことは重要である.

水試料中モリブデンの定量法として, 吸光光度法 ${ }^{5)}$, フ レームレス原子吸光光度法 ${ }^{6)}$ や ICP 発光分光分析法 ${ }^{7)}$ があ る. 環境水中モリブデンは一般に $\mu \mathrm{g} \mathrm{L}^{-1} レ$ レ゙以下で存在 し, 多くの場合, 定量には分離・前濃縮操作が必要である. その前処理方法として, 微晶質トリフェニルメタン ${ }^{8)}$, 硝 酸セルロース樹脂9), ポリウレタンフォーム ${ }^{10)}$ 等への吸着 捕集を利用した固相抽出法が開発されてきた.

本研究では, Sep-Pak CM カートリッジにジルコニゥム を担持させたジルコニウム担持 Sep-Pak (Zr-SP) を調製し, このジルコニウムがモリブデンに対して吸着特性があるこ とを見いだした。これを利用して，現場固相抽出法による 環境水中モリブデンの捕集・濃縮分析法を確立した。現場 固相抽出法 ${ }^{11)}$ とは, 試料水採取現場において採取後直ちに 迅速かつ簡便に分析対象化学種の捕集・濃縮操作が可能な 方法である. さらに, 捕集後はゴムキャップで密閉保存で きることから，現場で捕集した分析対象化学種を污染・損 失することなく, 安全に運搬が可能となる. 本研究では,

\footnotetext{
${ }^{\circledR}$ E-mail : okumura@riko.shimane-u.ac.jp

${ }^{1}$ 島根大学大学院総合理工学研究科 : 690-8504 島根県松江市西 川津町 1060
}

確立した分析法を島根県の斐伊川等に適用し，県東部にあ るモリブデン鉱山由来と考えられる河川水中モリブデンの 濃度分布を明らかにした。

$$
2 \text { 実験 }
$$

\section{$2 \cdot 1$ 試薬及び装置}

$\mathbf{2} \cdot \mathbf{1} \cdot 1$ 試薬 モリブデン標準溶液 $\left(1000 \mathrm{mg} \mathrm{L}^{-1}\right)$ : $1000 \mathrm{mg} \mathrm{L}^{-1}$ モリブデン標準液（和光純薬工業製）を原液 として, 水で適宜希棌して用いた。

ジルコニウム溶液 $\left(0.25 \mathrm{~mol} \mathrm{~L}^{-1}\right)$ : オキシ硝酸ジルコニ ウム二水和物 (特級, キシダ化学製) $66.82 \mathrm{~g}$ に $1 \mathrm{~mol} \mathrm{~L}^{-1}$ 塩酸を加えて $1 \mathrm{~L}$ とした. その後, 孔径 $0.45 \mu \mathrm{m}$ のメンブ レンフィルター（MILLIPORE 製 HAWP04700）で沪過し用 いた。 これを水で希釈してカラム調製試薬として用いた.

酒石酸ナトリウムカリウム溶液 $\left(1 \mathrm{~mol} \mathrm{~L}^{-1}\right):(+)$ - 酒石 酸ナトリウムカリウム四水和物 (特級, 関東化学製) $141.26 \mathrm{~g}$ を水に溶かし, $500 \mathrm{~mL}$ とした. 使用の度に適宜希 釈して用いた.

$\mathbf{2 \cdot 1 ・ 2}$ 装置 モリブデンの定量には日立製 Z-5000 型 グラファイト炉原子吸光光度計を使用した．原子吸光光度 計による測定条件を Table 1 に示す. pH の測定には堀場製 F-23 型ガラス複合電極 $\mathrm{pH}$ メーターを用いた。

\section{$2 \cdot 2$ 定量操作}

2・2・1 ジルコニウム担持 Sep-Pak の調製 実験操作

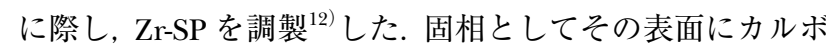
キシル基を有する陽イオン交換基結合型シリカゲル（粒径 $37 〜 55 \mu \mathrm{m}$ ) を充填したSep-Pak CMカートリッジ（Waters

Table 1 Instrumental operating conditions

\begin{tabular}{lcc}
\hline Operating step & Temperature $/{ }^{\circ} \mathrm{C}$ & Time $/ \mathrm{s}$ \\
\hline Drying 1 & $80-120$ & 50 \\
Drying 2 & $120-300$ & 20 \\
Ashing & 1000 & 20 \\
Atomizing & 2800 & 5 \\
Cleaning & 2800 & 5 \\
\hline
\end{tabular}

Wavelength, $313.3 \mathrm{~nm}$; lamp current, $17 \mathrm{~mA}$; argon gas flow rate, $30 \mathrm{~mL} \min ^{-1}$ (except during atomizing step). 


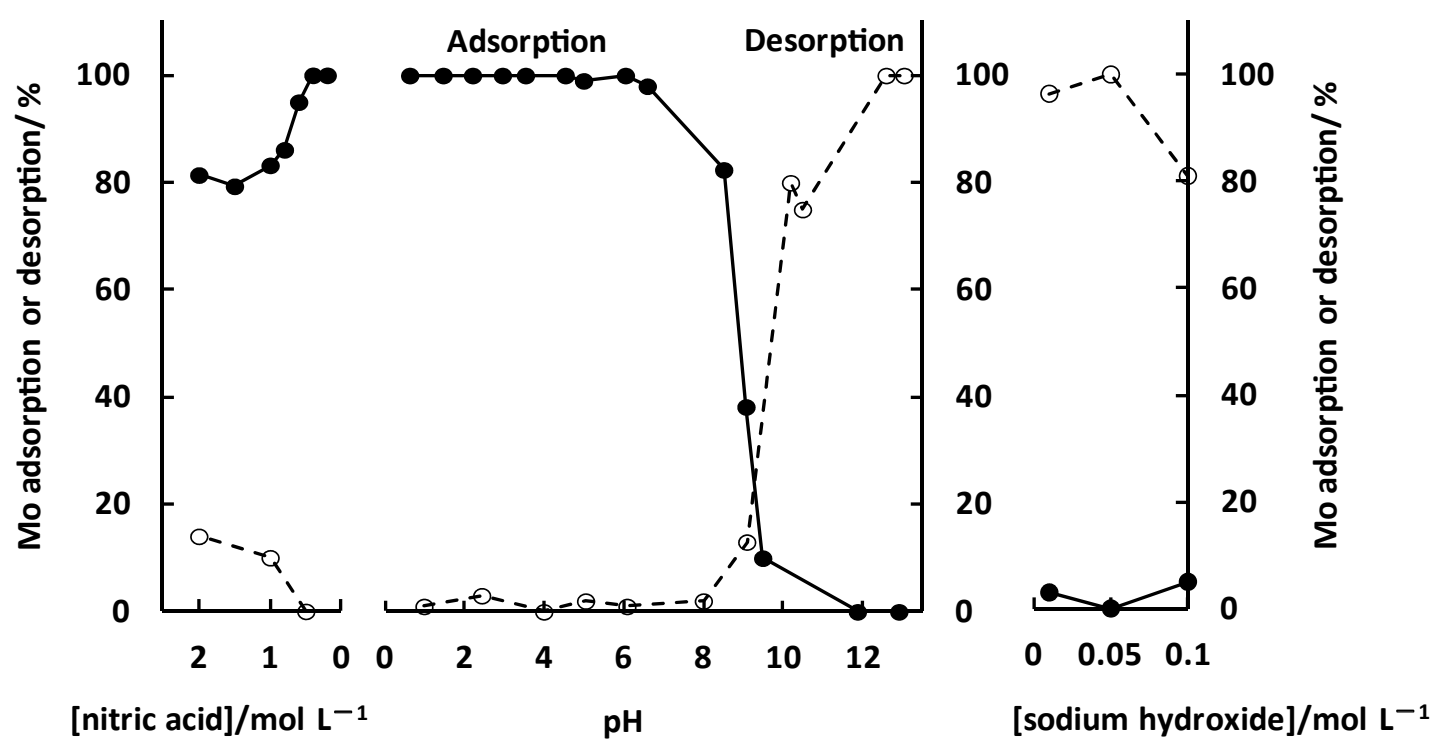

Fig. 1 Effect of $\mathrm{pH}$ on the adsorption or desorption of molybdenum

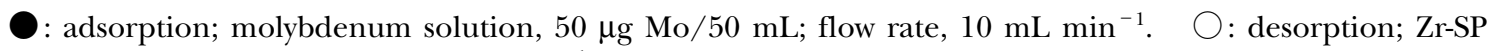

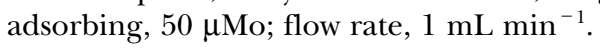

製, 長さ $4 \mathrm{~cm}$ ）に水 $5 \mathrm{~mL}, 2 \mathrm{~mol} \mathrm{~L}^{-1}$ 塩化ナトリウム $5 \mathrm{~mL}$, 水 $50 \mathrm{~mL}, 0.25 \mathrm{~mol} \mathrm{~L}^{-1}$ 塩酸 $5 \mathrm{~mL}$, 水 $50 \mathrm{~mL}$ を順 次通し, カラムを洗浄・コンディショニングした. 次に, $0.1 \mathrm{~mol} \mathrm{~L}^{-1}$ オキシ硝酸ジルコニウム $-1.0 \mathrm{~mol} \mathrm{~L}^{-1}$ 塩酸溶 液 $50 \mathrm{~mL}$ (通水速度 $4 \mathrm{~mL} \mathrm{~min}^{-1}$ ), 水 $30 \mathrm{~mL}, 1 \mathrm{~mol} \mathrm{~L}^{-1}$ 水酸化ナトリウム (通水速度 $25 \mathrm{~mL} \mathrm{~min}^{-1}$ ), 水 $50 \mathrm{~mL}$, $0.25 \mathrm{~mol} \mathrm{~L}^{-1}$ 塩酸 $10 \mathrm{~mL}$, 水 $50 \mathrm{~mL}$ を順次通すことでカラ ムにジルコニウムを担持させて，Zr-SP 調製した，調製 した Zr-SP は密閉し, 暗所で保存した，カラムに溶液を通 す際の通水速度は, ペリスタポンプにより調節した。

2・2・2 ジルコニウム担持 Sep-Pak ヘのモリブデンの吸 脱着操作 モリブデン含有水 $50 \mathrm{~mL}$ を $50 \mathrm{~mL}$ 用シリン ジに採取した．酸調整溶液として $10 \mathrm{~mol} \mathrm{~L}^{-1}$ 硝酸を $1 \mathrm{~mL}$ 添加して試料溶液を $0.2 \mathrm{~mol} \mathrm{~L}^{-1}$ 硝酸濃度に調整した後, Zr-SP に通した。なお，試料溶液をカラムに通す際の通水 速度が 1〜 $50 \mathrm{~mL} \mathrm{~min}^{-1}$ の範囲で, モリブデンは定量的に カラムに吸着される. 次に溶離液として $0.05 \mathrm{~mol} \mathrm{~L}^{-1}$ 水酸 化ナトリウム $-0.05 \mathrm{~mol} \mathrm{~L}^{-1}$ 酒石酸ナトリウムカリウム混 合溶液 $9 \mathrm{~mL}$ を, 溶離を容易にするために吸着操作とは逆 方向から Zr-SP に通水速度 $0.5 \mathrm{~mL} \mathrm{~min}^{-1}$ で通してモリブデ ンを溶離させた．溶出液に $5 \mathrm{~mol} \mathrm{~L}^{-1}$ 硝酸を $1 \mathrm{~mL}$ 添加し て酸調整した後に, 黒鉛炉原子吸光法（GFAAS）を用いて 測定した.

実試料の分析に際しては, 採水後直ちに現場でモリブデ ンを吸着捕集し，Zr-SP を密閉して運搬・保存した，研究 室に持ち帰った後, 溶離し, GFAAS で測定した。

カラムに溶液を通す際の通水速度は, 実験室においては ペリスタポンプの使用により調節し，また現場では計時す
ることにより手動で流速を調節した.

\section{3 結果と考察}

$3 \cdot 1$ ジルコニウム担持 Sep-Pak ヘのモリブデンの吸着 モリブデンの Zr-SP の吸着に及ぼす $\mathrm{pH}$ の影響につい て, $50 \mu \mathrm{g} \mathrm{L}^{-1}$ モリブデン溶液 $50 \mathrm{~mL}$ を通水速度 $10 \mathrm{~mL}$ $\min ^{-1}$ で通して検討した。 その結果を Fig. 1 に示す。モリ ブデンは $\mathrm{pH} 7$ 以下で定量的に吸着した。 また，それ以上 の $\mathrm{pH}$ では吸着率は減少し，pH 12 以上ではモリブデンは 吸着しなかったまた，硝酸濃度の影響について検討を 行ったところ, モリブデンは $0.4 \mathrm{~mol} \mathrm{~L}^{-1}$ 硝酸濃度以下で 定量的に吸着し，それ以上では吸着率は減少した。 これら の結果から, 水試料を $0.2 \mathrm{~mol} \mathrm{~L}^{-1}$ 硝酸濃度に酸調整して Zr-SP に通すことにより捕集することとした．

モリブデンを Zr-SP に捕集する際の水試料の通水速度の 影響について，モリブデン溶液 $50 \mathrm{~mL}$ を通水速度 1 ～50 $\mathrm{mL} \mathrm{min}{ }^{-1}$ でZr-SP に通して検討を行ったところ, いずれの 通水速度に扔いても定量的に吸着した．現場でのシリンジ を用いる操作では動力源を用いないことから，捕集時にお ける水試料の通水速度は, 手動による操作が可能な約 10 $\mathrm{mL} \min ^{-1}$ とした.

また, ブレイクスルー法により Zr-SP のモリブデンの吸 着容量を求めた. $10 \mathrm{mg} \mathrm{L}^{-1}$ モリブデン溶液を $0.2 \mathrm{~mol} \mathrm{~L}^{-1}$ 硝酸濃度に調整し, 通水速度 $10 \mathrm{~mL} \mathrm{~min}^{-1}$ で Zr-SP に通し たところ，モリブデンは $125 \mathrm{~mL}$ 通したところで漏出した. このことから， Zr-SP によるモリブンデンの吸着容量は 1.0 mg cartridge - $^{-1}$ である.

$50 \mu \mathrm{g} \mathrm{L}^{-1}$ モリブデン溶液 $\left(0.2 \mathrm{~mol} \mathrm{~L}^{-1}\right.$ 硝酸濃度に酸調 


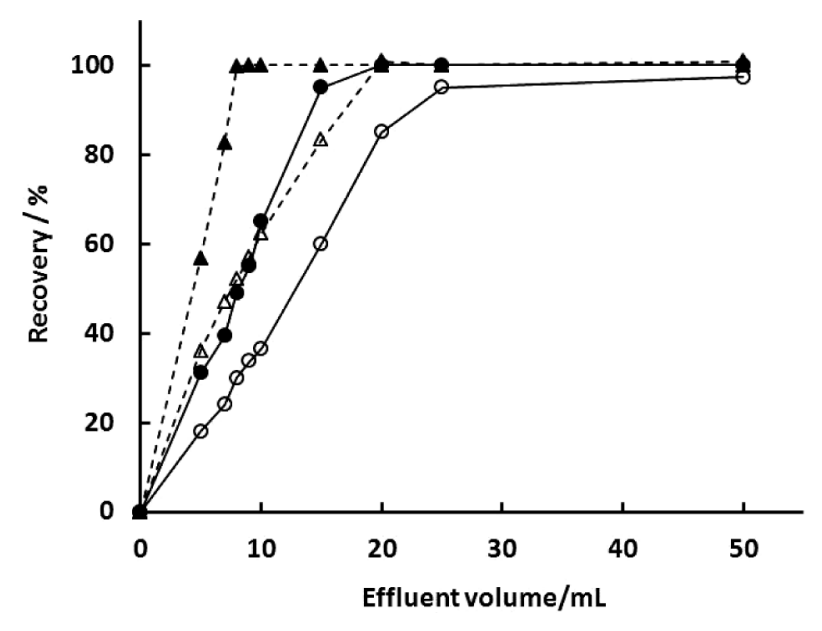

Fig. 2 Effect of the volume and flow rate of the eluent on molybdenum elution

: mixture of $0.05 \mathrm{~mol} \mathrm{~L}^{-1}$ sodium hydroxide and $0.01 \mathrm{~mol} \mathrm{~L}^{-1}$ potassium sodium tartrate; flow rate, 0.5 $\mathrm{mL} \min ^{-1}$. $\bigcirc$ : mixture of $0.05 \mathrm{~mol} \mathrm{~L}^{-1}$ sodium hydroxide and $0.01 \mathrm{~mol} \mathrm{~L}^{-1}$ potassium sodium tartrate; flow rate, $1 \mathrm{~mL} \mathrm{~min}{ }^{-1}$. $\quad \Delta$ : mixture of $0.05 \mathrm{~mol} \mathrm{~L}^{-1}$ sodium hydroxide and $0.05 \mathrm{~mol} \mathrm{~L}^{-1}$ potassium sodium tartrate; flow rate, $0.5 \mathrm{~mL} \mathrm{~min}^{-1} . \quad \triangle$ : mixture of 0.05 mol L ${ }^{-1}$ sodium hydroxide and $0.01 \mathrm{~mol} \mathrm{~L}^{-1}$ potassium sodium tartrate; flow rate, $1 \mathrm{~mL} \mathrm{~min}^{-1}$.

整） $50 \mathrm{~mL}$ をジルコニウムの担持されていない Sep-Pak $\mathrm{CM}$ カートリッジ自体に通したところ, モリブデンの吸着 率は 5 \% 以下であった. モリブデンが Zr-SP のジルコニウ ムにより効果的に吸着されていることが示された. 水溶液 に溶存するモリブデンはモリブデン酸として存在し, $\mathrm{pH}$ 5.1 以上で $\mathrm{MoO}_{4}{ }^{2-}$ が, $\mathrm{pH} \mathrm{3.6〜5.1} \mathrm{では} \mathrm{HMoO}_{4}{ }^{-}$が優勢 で，それ以下の $\mathrm{pH}$ では縮合型モリブデン酸イオンが優勢 であると推定される ${ }^{13)}$ 。このためモリブデンは中性領域か ら弱酸性性領域にかけて主に単体のモリブデン酸㓌イオン が，また酸性領域では主に縮合したモリブデン酸陰イオン が, 固相表面のジルコニウムに配位化学種として表面錯体 を形成して, 結合しているものと推察される ${ }^{14)}$.このため, ジルコニウムに対して配位化学種となりうるようなオキソ 酸陰イオンは，同様に吸着されると考えられる.

\section{$3 \cdot 2$ ジルコニウム担持 Sep-Pak からのモリブデンの溶離}

$\mathbf{3 \cdot 2 \cdot 1} \mathrm{pH}$ の影響 $\mathrm{Zr}-\mathrm{SP}$ からのモリブデンの脱離に 及ぼす $\mathrm{pH}$ の影響について, 液量 $50 \mathrm{~mL}$, 通水速度 $1 \mathrm{~mL}$ $\min ^{-1}$ で検討した. Fig. 1 に吸着と共に脱着の結果を示す. モリブデンの脱離は, 吸着と対照的な傾向を示した。 モリ ブデンは $\mathrm{pH} 8$ 以下ではほとんど脱離せず, それ以上の $\mathrm{pH}$ では溶離率が増加し, pH 12 付近において定量的な脱離が 起こった。 また水酸化ナトリウム濃度の影響について検討 を行った. $0.05 \mathrm{~mol} \mathrm{~L}^{-1}$ 水酸化ナトリウム溶液を溶離液と して用いたとき，モリブデンが定量的に脱離したが， 0.1 $\mathrm{mol} \mathrm{L}^{-1}$ 水酸化ナトリウムを用いたとき，溶離率は $81 \%$ であった.この結果から, 溶離液として $0.05 \mathrm{~mol} \mathrm{~L}^{-1}$ 水酸 化ナトリウム溶液 $50 \mathrm{~mL}$ 用いることで, モリブデンを定量 的に溶離できることが分かった.

溶離に際し, $0.05 \mathrm{~mol} \mathrm{~L}^{-1}$ 水酸化ナトリウム溶液 $50 \mathrm{~mL}$ の Zr-SP に対する通水速度について $1 \sim 5 \mathrm{~mL} \mathrm{~min}^{-1}$ の範囲 で検討した，通水速度の影響は大きく，速度が $1 \mathrm{~mL} \mathrm{~min}^{-1}$ を越えると回収率は低下した。このため, 溶離に際し, 通 水速度は $1 \mathrm{~mL} \mathrm{~min}{ }^{-1}$ 以下にする必要がある.

$3 \cdot 2 \cdot 2$ 溶離液量の少量化 モリブデンを濃縮回収す るため, 溶離液量の少量化と溶離の際の通水速度について 検討を行った. 溶離液として $0.05 \mathrm{~mol} \mathrm{~L}^{-1}$ 水酸化ナトリウ ム溶液を用いたとき，90％以上のモリブデンを溶離する ためには $20 \mathrm{~mL}$ 以上の溶離液量が必要であった. 濃縮効果 を上げるために，さらに酒石酸塩を含む溶離液について濃 縮回収の検討を行った. $0.05 \mathrm{~mol} \mathrm{~L}^{-1}$ 水酸化ナトリウム溶 液に, 0.01 及び $0.05 \mathrm{~mol} \mathrm{~L}^{-1}$ となるように酒石酸ナトリウ ムカリウム溶液を添加した混合溶液を溶離液として用い, また溶離液の通水速度を $0.5 \mathrm{~mL} \mathrm{m^{-1 }}$ と $1 \mathrm{~mL} \mathrm{~min}^{-1}$ にし て比較検討した．検討結果を Fig. 2 に示す．溶離液として $0.05 \mathrm{~mol} \mathrm{~L}^{-1}$ 水酸化ナトリウム $-0.05 \mathrm{~mol} \mathrm{~L}^{-1}$ 酒石酸ナト リウムカリウム混合溶液の液量 $8 \mathrm{~mL}$ 以上を流速 $0.5 \mathrm{~mL}$ $\min ^{-1}$ で通水したとき，モリブデンを定量的に回収できる ことが分かった。この結果から, 濃縮回収を行う際は, 溶 離液として $0.05 \mathrm{~mol} \mathrm{~L}^{-1}$ 水酸化ナトリウム $-0.05 \mathrm{~mol} \mathrm{~L}^{-1}$ 酒石酸ナトリウムカリウム混合溶液 $9 \mathrm{~mL}$ を通水すること により溶離し, 酸調整として $5 \mathrm{~mol} \mathrm{~L}^{-1}$ 硝酸 $1 \mathrm{~mL}$ を添加 して GFAASによって定量した.この溶離法により濃縮倍 率 5 倍での回収が可能である.

このように，ジルコニウムに結合したモリブデンは塩基 性溶液及び酒石酸塩溶液で脱離される。これは, ジルコニ ウム表面に結合していたモリブデン酸イオンと水酸化物イ オン及び酒石酸イオンが配位子交換することにより脱離さ れるためと考えられる. 特に, 水酸化物イオンに比べて酒 石酸イオンの脱離の効果が大きいのは, ジルコニウムに対 して酒石酸イオンの方がより強く結合し, 配位子交換を促 進するためと推察される.

\section{$3 \cdot 3$ 共存イオンの影響}

本分離濃縮定量法において共存イオンによる分析值への 影響について検討した. 塩分の影響について人工海水 ${ }^{14)}$ と その希釈溶液 [塩分 $0 \sim 34 \%$; この場合の塩分とは, 海水 $1 \mathrm{~kg}$ に溶解している固形物質の全量をグラムで表した濃度 のことであり, \% (千分率) で表記する]を用いて $50 \mu \mathrm{g} \mathrm{L}^{-1}$ モリブデン溶液 $50 \mathrm{~mL}$ を調製し, 本法によりモリブデンを 定量した. 人工海水は $\mathrm{Na}^{+}\left(10.5 \mathrm{~g} \mathrm{~L}^{-1}\right), \mathrm{Mg}^{2+}(1.27$ $\left.\mathrm{g} \mathrm{L}^{-1}\right), \mathrm{Ca}^{2+}\left(0.40 \mathrm{~g} \mathrm{~L}^{-1}\right), \mathrm{K}^{+}\left(0.38 \mathrm{~g} \mathrm{~L}^{-1}\right), \mathrm{Sr}^{2+}$ 
$\left(8 \mathrm{mg} \mathrm{L}^{-1}\right)$ などの陽イオンと, $\mathrm{Cl}^{-}\left(19.0 \mathrm{~g} \mathrm{~L}^{-1}\right), \mathrm{SO}_{4}{ }^{2-}$ $\left(2.6 \mathrm{~g} \mathrm{~L}^{-1}\right), \mathrm{HCO}_{3}{ }^{-}\left(0.14 \mathrm{~g} \mathrm{~L}^{-1}\right), \mathrm{Br}^{-}\left(64 \mathrm{mg} \mathrm{L}^{-1}\right)$, $\mathrm{H}_{3} \mathrm{BO}_{3}\left(26 \mathrm{mg} \mathrm{L}^{-1}\right), \mathrm{F}^{-}\left(1 \mathrm{mg} \mathrm{L}{ }^{-1}\right)$ などの陰イオンを含 む. これらの化学種は, 通常の河川水や湖沼水に普遍的に 溶存し, 一般に $\mathrm{mg} \mathrm{L}^{-1}$ オーダーあるいはそれ以下である. 検討の結果, モリブデンは $1 \%$ 以下の低い塩分濃度以下で 定量的に回収できた。しかし， $2 \%$ 以上の高い塩分範囲で は塩分の上昇と共にモリブデンの回収率は低下し， $34 \%$ では $36 \%$ であった.

通常の河川水に溶存する個々の陽イオン, 陰イオンにつ いてさらに検討をした，その結果を Table 2 に示す．いず れのイオンについても, 河川水の濃度レベルでは本法によ る定量に影響しない.このように, 本法は河口域のような 塩分の薄い汽水や河川水等の環境水に適用可能である.

\section{$3 \cdot 4$ 回収, 分析精度, その他の因子}

モリブデン標準液を用いて 0 〜 $50 \mu \mathrm{g} \mathrm{L}^{-1}$ の範囲で, $2 \cdot 2 \cdot 2$ の濃縮操作に従って検量線を作成したところ, 直線 性の良い検量線（0.996）が得られた. Table 3 に純水にお

Table 2 Effect of diverse ions

\begin{tabular}{lcc}
\hline Ion & Ion concentration $/ \mathrm{mg} \mathrm{L}^{-1}$ & Recovery/\% \\
\hline $\mathrm{Na}^{+}$ & 10000 & 96 \\
$\mathrm{~K}^{+}$ & 5000 & 93 \\
$\mathrm{Ca}^{2+}$ & 5000 & 88 \\
$\mathrm{Mg}^{2+}$ & 2000 & 104 \\
$\mathrm{Fe}^{3+}$ & 1 & 98 \\
$\mathrm{Cu}^{2+}$ & 5 & 97 \\
$\mathrm{Al}^{3+}$ & 5 & 94 \\
$\mathrm{~F}^{-}$ & 1 & 88 \\
$\mathrm{Cl}^{-}$ & 10000 & 100 \\
$\mathrm{NO}_{3}{ }^{-}$ & 2.5 & 98 \\
$\mathrm{PO}_{4}{ }^{3-}$ & 2.5 & 93 \\
$\mathrm{SO}_{4}{ }^{2-}$ & 500 & 88 \\
\hline
\end{tabular}

けるモリブデンの回収とその相対標準偏差 (RSD), 及び実 試料として河川水へのモリブデンの添加回収試験の結果を 示す.モリブデンはいずれの試料水からも定量的に回収で き, また, 相対標準偏差は, 純水について $3 \%$, 河川水に ついて $3 \sim 6 \%$ となり, 回収率及び分析精度とも良好な結 果を得ることができた. また，Zr-SPに保持されたモリブ

Table 4 Determination of molybdenum in river water

\begin{tabular}{|c|c|c|}
\hline \multicolumn{2}{|c|}{ Sampling point } & \multirow{2}{*}{$\begin{array}{c}\text { Molybdenum } / \mu \mathrm{g} \mathrm{L}^{-1} \\
<0.2\end{array}$} \\
\hline Mabashi river & St. 1 & \\
\hline \multirow[t]{4}{*}{ (23 June 2011) } & St. 2 & 1.1 \\
\hline & St. 3 & 1.0 \\
\hline & St. 4 & 1.0 \\
\hline & St. 5 & 2.5 \\
\hline \multirow{7}{*}{$\begin{array}{l}\text { Hii river } \\
(23 \text { October 2011) }\end{array}$} & St. 6 & 1.0 \\
\hline & St. 7 & 0.9 \\
\hline & St. 8 & 1.0 \\
\hline & St. 9 & 1.1 \\
\hline & St. 10 & 1.5 \\
\hline & St. 11 & 1.5 \\
\hline & St. 12 & 1.6 \\
\hline \multirow{7}{*}{$\begin{array}{l}\text { Hakuta river } \\
\text { (2 November 2011) }\end{array}$} & St. 13 & 1.4 \\
\hline & St. 14 & 1.7 \\
\hline & St. 15 & 1.7 \\
\hline & St. 16 & 1.7 \\
\hline & St. 17 & 1.5 \\
\hline & St. 18 & 1.7 \\
\hline & St. 19 & 1.6 \\
\hline \multirow{6}{*}{$\begin{array}{l}\text { Aka river } \\
\text { (5 December 2011) }\end{array}$} & St. 20 & 1.6 \\
\hline & St. 21 & 1.7 \\
\hline & St. 22 & 1.5 \\
\hline & St. 23 & 5.6 \\
\hline & St. 24 & 4.1 \\
\hline & St. 25 & 3.9 \\
\hline \multirow{5}{*}{$\begin{array}{l}\text { Ayou river } \\
\text { (11 October 2012) }\end{array}$} & St. 26 & 0.8 \\
\hline & St. 27 & 2.0 \\
\hline & St. 28 & 19.6 \\
\hline & St. 29 & 13.6 \\
\hline & St. 30 & 9.7 \\
\hline
\end{tabular}

Table 3 Analytical results and recoveries of molybdenum in pure water and environmental water samples

\begin{tabular}{|c|c|c|c|c|c|}
\hline \multirow{2}{*}{ Sample } & \multirow{2}{*}{$\begin{array}{l}\text { Mo added/ } \\
\qquad \mu \mathrm{g} \mathrm{L}^{-1}\end{array}$} & \multirow{2}{*}{$\begin{array}{c}\text { Mo found/ } \\
\mu \mathrm{g} \mathrm{L}^{-1}\end{array}$} & \multicolumn{2}{|c|}{ Recovery } & \multirow{2}{*}{$\begin{array}{c}\text { RSD } \\
(n=5)\end{array}$} \\
\hline & & & $\mu \mathrm{g} \mathrm{L^{-1 }}$ & $\%$ & \\
\hline \multirow[t]{2}{*}{ Pure water } & 2.0 & 2.1 & 2.1 & 104 & 3.1 \\
\hline & 5.0 & 5.0 & 5.0 & 100 & 2.7 \\
\hline \multirow{4}{*}{$\begin{array}{l}\text { River water } \\
\text { (Hii river) }\end{array}$} & - & 1.5 & - & - & - \\
\hline & 2.0 & 3.6 & 2.1 & 104 & 5.9 \\
\hline & 5.0 & 6.5 & 5.0 & 100 & 3.2 \\
\hline & 10.0 & 11.4 & 9.9 & 99 & 3.9 \\
\hline \multirow{4}{*}{$\begin{array}{l}\text { River water } \\
\text { (Ayou river) }\end{array}$} & - & 16.2 & - & - & - \\
\hline & 2.0 & 18.3 & 2.1 & 103 & 5.6 \\
\hline & 5.0 & 21.2 & 5.0 & 100 & 6.0 \\
\hline & 10.0 & 26.5 & 10.3 & 103 & 6.1 \\
\hline
\end{tabular}

River water samples were taken from Hii river and Ayou river, Japan, respectively. 


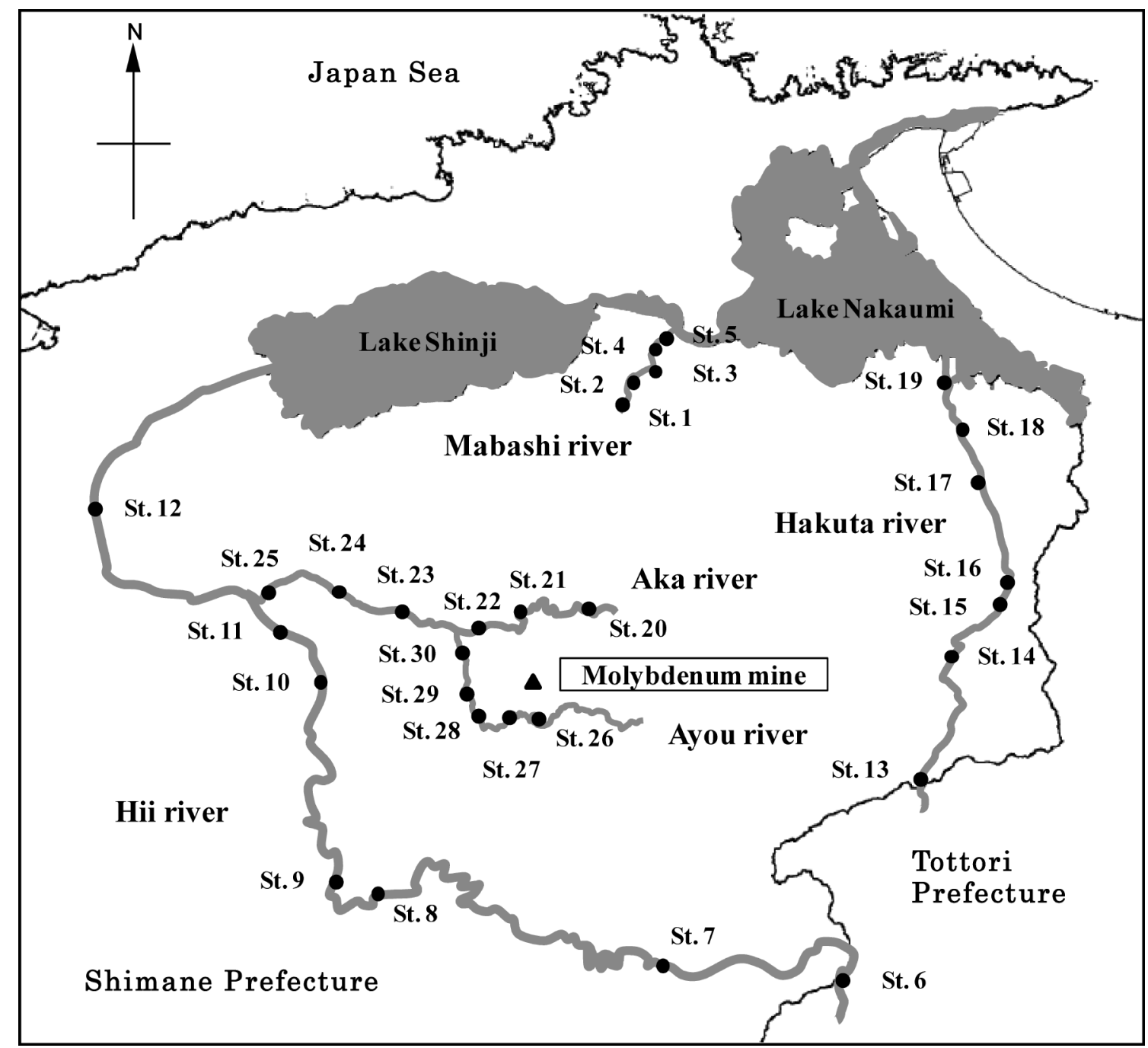

Fig. 3 Map showing the sampling points of rivers in the eastern area of Shimane Prefectute, Japan

デンは, Zr-SP の両端をゴムキャップで密栓して試料溶液 を保存することで 20 日間は安定であった。

水試料 $200 \mathrm{~mL}$ を $200 \mathrm{~mL}$ 用シリンジに採り Zr-SPに通す ことにより濃縮効果を調べた．水試料として河川水及び純 水を用いて検討したところ，モリブデンはいずれも定量的 に回収できた，この結果，本法では， $200 \mathrm{~mL}$ の水試料を 用いることにより，モリブデンの濃縮倍率 20 倍が可能で ある。

\section{$3 \cdot 5$ 島根県の河川水試料の分析結果}

本研究により確立した分析法を用いて, 島根県東部にあ る馬橋川，斐伊川，伯太川，赤川及び阿用川にて採取した 河川水に含有するモリブデンを定量した．水試料の採取地 点を Fig. 3 に示す. 水試料は採水器で採取後, 直ちに 50 $\mathrm{mL}$ 注射器に分取し, $2 \cdot 2$ の定量操作に従いモリブデンを $\mathrm{Zr}-\mathrm{SP}$ に捕集した。 この Zr-SP を研究室に持ち帰り, 溶離後 酸調整して GFAASにより定量した．本法による分析の結
果を Table 4 に示す．馬橋川，斐伊川及び伯太川において モリブデン濃度はほほ $2 \mu \mathrm{g} \mathrm{L}^{-1}$ 以下であった. しかし, 赤 川に流入する阿用川では，上流部（St. 26, 27）で $0.8 \sim 2.0$ $\mu \mathrm{g} \mathrm{L}^{-1}$ と低い濃度であったが, 中流部（St. 28）において $19.6 \mu \mathrm{g} \mathrm{L}^{-1}$ とモリブデン濃度の急増が見られ, 下流に向 かって順次濃度が下がり，下流部（St. 30）で $9.7 \mu \mathrm{g} \mathrm{L}^{-1}$ で あった，阿用川の流入する赤川では，流入前の上流部（St. 20, 21, 22）で $1.5 \sim 1.7 \mu \mathrm{g} \mathrm{L}^{-1}$ であったが，流入後の流域 (St. 23) では $5.6 \mu \mathrm{g} \mathrm{L}^{-1}$ に上昇し，下流（St. 24, 25）では $3.9 \sim 4.1 \mu \mathrm{g} \mathrm{L}^{-1}$ となった. 島根県東部にモリブデンの鉱床 が点在して抢り，阿用川の流れる地域には大東，清久鉱山 がある2．このように，モリブデン鉱山からの水が直接流 入する阿用川ではモリブデン濃度が高く，この影響は阿用 川の流入する赤川にまで及ぶ．しかし，これらの河川中で 最大の水量をもつ斐伊川では, 赤川河川水が流入するもの の顕著な影響は見られなかった。 


\section{文献}

1) 日本水道協会 : 上水試験方法解説編, 1993 年版, p. 338 (1993).

2) 日本の地質中国地方編集委員会 : 日本の地質 (7) 中国地方, p. 173 (1987), (共立).

3) 野田 滋, 高見有一, 山根忠昭, 山路 健: 島根 県農業試験場研究報告, 28, 27 (1994).

4) 林 英夫, 八幡策郎：中國農業試験場報告, 3, 556 (1958).

5) 川久保進, 萩原清志, 岩附正明 : 分析化学 (Bunseki Kagaku), 46, 381 (1997).

6) 木村 優, 後藤千春, 谷 桃子 : 分析化学 (Bunseki Kagaku), 38, 529 (1989).

7) 鈴木康弘, 白崎俊浩, 中口 譲, 小池祐一, 平木敬 三：分析化学 (Bunseki Kagaku), 43, 1127 (1994).
8) Q. Li, X. Zha, X. Guan, G. Liu : Anal. Chim. Acta, 562, 44 (2006).

9) I. Nukatsuka, Y. Shimizu, K. Ohzeki : Anal. Sci., 20, 1033 (2004).

10) S. L. C. Ferreira, H. C. dos Santos, R. C. Campios : Talanta, 61, 789 (2003).

11) 奥村 稔, 藤永 薰, 清家 泰 : 分析化学 (Bunseki Kagaku), 54, 1061 (2005).

12) M. Okumura, Liu Tong, K. Fujinaga, Y. Seike : Fresenius J. Anal. Chem., 370, 104 (2001).

13) 山崎秀夫, 辻本憲一，倉田志郎，平木敬三，西川泰 治：分析化学 (Bunseki Kagaku), 26, 424 (1979).

14) W. Stumm, J. J. Morgan : “Aquatic Chemistry”, 3rd ed., (1996), (Wiley Interscience, New York).

15) J. P. Riley, G. Skirrow : “Chemical Oceanography 1", p. 648 (1965), (Academic Press, New York).

\title{
On-site Solid Phase Extraction for Determination of Trace Molybdenum in
} River Water Samples by Graphite Furnace Atomic Absorption Spectrometry

\author{
Takayuki YAmAGUChI ${ }^{1}$, Yasushi SEIKE ${ }^{1}$ and Minoru OKUMURA ${ }^{\circledR 1}$ \\ ${ }^{\circledR}$ E-mail : okumura@riko.shimane-u.ac.jp
}

${ }^{1}$ Interdisciplinary Graduate School of Science and Engineering, Shimane University, 1060, Nishikawatsu-cho, Matsue-shi, Shimane 690-8504

(Received March 19, 2013; Accepted August 19, 2013)

A simple and rapid in situ separation and preconcentration method for the determination of molybdenum in environmental waters has been developed based on solid-phase extraction using a Sep-Pak CM cartridge loaded with zirconium (Zr-SP), followed by the determination of molybdenum with GFAAS. The adsorption and desorption behaviors of molybdenum on a $\mathrm{Zr}$-SP were strongly affected by the $\mathrm{pH}$ of the solution. Molybdenum in the solution was quantitatively adsorbed on a Zr-SP at lower than $\mathrm{pH}$ 7. On the other hand, the desorption of molybdenum adsorbed on the $\mathrm{Zr}-\mathrm{SP}$ was quantitatively made with solutions of higher than $\mathrm{pH}$ 12. A molybdenum solution adjusted to $0.2 \mathrm{~mol} \mathrm{~L}^{-1}$ nitric acid was passed through a $\mathrm{Zr}$-SP at a flow rate of $10 \mathrm{~mL} \mathrm{~min}{ }^{-1}$ for the adsorption of molybdenum. In field work, a guraduated syringe was used for the collection of molybdenum to make these operations simple and easy by hand in a short time. A mixture of $0.05 \mathrm{~mol} \mathrm{~L}^{-1}$ sodium hydroxide and $0.05 \mathrm{~mol} \mathrm{~L}^{-1}$ potassium sodium tartrate as an elute was found to more easily eluent molybdenum from $\mathrm{Zr}$-SP than a $0.05 \mathrm{~mol} \mathrm{~L}^{-1}$ sodium hydroxide solution. Therefore, the molybdenum adsorbed on the $\mathrm{Zr}-\mathrm{SP}$ was eluted by passing $9 \mathrm{~mL}$ of a mixture of $0.05 \mathrm{~mol} \mathrm{~L}^{-1}$ sodium hydroxide and 0.05 mol L ${ }^{-1}$ potassium sodium tartrate through the $\mathrm{Zr}-\mathrm{SP}$ at a flow rate of $0.5 \mathrm{~mL} \mathrm{~min}{ }^{-1}$. The eluted molybdenum was determined with GFAAS after adjusting the acidity with nitric acid. The established method was successfully applied to river water samples taken from some rivers in the eastern area of Shimane Prefecture, Japan. Relatively high concentrations of molybdenum were found in river water samples near molybdenum mines located in this area.

Keywords: molybdenum determination; separation; preconcentration; solid-phase extraction; graphite furnace atomic absorption spectrometry; river water. 